\title{
Dendrimers as Innovative Radiopharmaceuticals in
}

\section{Cancer Radionanotherapy}

\author{
Flonja Liko ${ }^{a, b}$, François Hindré $e^{a, *}$ and Eduardo Fernandez-Megia ${ }^{b, *}$ \\ ${ }^{a}$ INSERM U 1066, 'Micro et Nanomédecines biomimétiques - MINT', and Plateforme de Radiobiologie et \\ d'IMagerie EXpérimentale, PRIMEX, SFR ICAT 4208, Université Angers, UMR-S1066, 49933 Angers, \\ Cedex 9, France
}

${ }^{b}$ Centro Singular de Investigación en Química Biolóxica e Materiais Moleculares (CIQUS) and Departamento de Química Orgánica, Universidade de Santiago de Compostela, Jenaro de la Fuente s/n, 15782 Santiago de Compostela, Spain.

KEYWORDS: dendrimers, radionanomedicine, radiotherapy, cancer, radioimmunotherapy

\begin{abstract}
Radiotherapy is one of the most commonly used cancer treatments, with an estimate of $40 \%$ success that could be improved further if more efficient targeting and retention of radiation at the tumor site were achieved. This review focuses on the use of dendrimers in radionanotherapy, an emerging technology aimed to improve the efficiency of radiotherapy by implementing nanovectorization, an already established praxis in drug delivery and diagnosis. The labeling of dendrimers with radionuclides also aims to reduce the dose of radiolabeled materials, and hence their toxicity and tumor resistance. Examples of radiolabeled dendrimers with alpha, beta and
\end{abstract}


Auger electron emitters are commented, along with the use of dendrimers in boron neutron capture therapy (BNCT). The conjugation of radiolabeled dendrimers to monoclonal antibodies for a more efficient targeting and the application of dendrimers in gene delivery radiotherapy are also covered.

\section{CONTENTS:}

1. Introduction

1.1. Nanovectorized radiotherapy drugs approved or under clinical trials

2. Dendrimers as Innovative Radiopharmaceuticals

2.1. Radiolabeled Dendrimers in Radiotherapy

2.1.1. Beta emitter radionuclide conjugates

2.1.2. Alpha emitter radionuclide conjugates

2.1.3. Auger electron emitter radionuclide conjugates

2.1.4. Dendrimers in Boron Neutron Capture Therapy

2.2. Dendrimer-Antibody Conjugates in Radioimmunotherapy

2.3. Dendrimers in Gene Delivery Radiotherapy

2.3.1. Dendrimers in Radiovirotherapy

2.3.2. Dendrimers in Combined Non-Viral Gene Delivery and Radiotherapy

3. Conclusions and Future Perspectives 


\section{INTRODUCTION}

Since the discovery of $X$ rays and radioactivity at the end of the $19^{\text {th }}$ century, and their introduction into clinical practice, radiotherapy has been used, along with surgery and chemotherapy, as a key modality in cancer treatment. Its powerful ability to cause tumor cell death lays mainly in the induction of irreparable DNA damage and cell cycle arrest. ${ }^{1}$ Approximately $50 \%$ of all cancer patients receive radiotherapy during the course of their illness ${ }^{2}$ with an estimated $40 \%$ success. $^{3}$ There are two ways to deliver radiation to the tumor sites. The most common approach in the clinical practice is external beam radiation, which delivers high-energy radiation (photons, protons or particle radiation) from outside the body to the tumor location. The second type is internal radiation, which is delivered by radionuclides into the tumor site. Radionuclide internal therapy can therefore reduce irradiation of healthy tissues with relatively low toxicity, in comparison to conventional chemotherapy and external beam radiotherapy.

The therapeutic effect of internal radiotherapy is due to the delivery of alpha $(\alpha)$, beta $\left(\beta^{-}\right)$or Auger electron emitters (Table 1) to the tumor site, resulting in tumor shrinkage or its total elimination, depending on the Linear Energy Transfer (LET) of the emitter (Table 2). As alpha particles are positively charged mono-energetic helium nuclei with the highest energy among particle emissions (LET $\sim 80 \mathrm{keV} / \mu \mathrm{m}$ ), they will interact in a range of penetration in tissue from 40 to 100 micrometers. This is consistent with the dimension of micro-metastatic lesions, so they are especially suited for localized irradiation of target cells with minimal toxicity to the surrounding normal cells. This radiation is particularly effective in killing cells, ${ }^{4}$ independently of their oxygenation state or cell cycle phase. ${ }^{5}$ Although human cancer cells can be eradicated in vitro after being hit by only a few alpha particles, ${ }^{6}$ these must reach the tumor cell nuclei to show an efficient cytocidal effect, not just the cell cytoplasm. ${ }^{7}$ 
Physico-chemical characteristics of Auger electrons are close with alpha particles with a tissue penetration from nanometers to a few micrometers. In comparison, $\beta^{-}$particles (high energy electrons from $\beta^{-}$decay) have the longest penetration range in tissue $(1-12 \mathrm{~mm})$. This is an important factor to consider regarding the size of the tumors potentially treated, as well as the targeting ligands and carriers for the $\beta^{-}$radionuclide. ${ }^{8}$ The $\beta^{-}$particle irradiation also leads to the generation of harmful free radical species in the presence of oxygen in tumor cells. Due to their lower LET compared to alpha particles, $\beta^{-}$particles have a lower killing efficacy, so higher concentrations of emitters are required for a comparable effect. ${ }^{9}$ Conversely, since the long path of $\beta^{-}$particles crosses multiple cells, a cross-fire effect is achieved that not only avoids the need to target every cancer cell with a radionuclide emitter, but also reduces the hurdle of an heterogeneous uptake in large tumors.

Finally, Auger electrons are low energy atomic orbital electrons emitted after electron capture (EC). ${ }^{10}$ Studies in vitro have shown Auger electrons as highly effective and specific in tumor cell killing when used in tandem with targeting vehicles that can direct them in close proximity to cellular DNA. ${ }^{11,12}$

Table 1: Radionuclides for tumor radiotherapy ${ }^{13-17}$ 


\begin{tabular}{|c|c|c|c|c|}
\hline Radionuclide & Half-life & $\begin{array}{c}\text { Decay } \\
\text { mode }\end{array}$ & $\begin{array}{c}\text { Energy } \\
\max (k e V)\end{array}$ & $\begin{array}{l}\text { Max } \\
\text { range in } \\
\text { tissue }\end{array}$ \\
\hline${ }^{80 \mathrm{~m}} \mathrm{Br}$ & $4.42 \mathrm{~h}$ & Auger & 3092.6 & $<10 \mathrm{~nm}$ \\
\hline${ }^{125} \mathrm{I}$ & $60 \mathrm{~h}$ & Auger & 185.77 & $10 \mathrm{~nm}$ \\
\hline${ }^{225} \mathrm{Ac}$ & $10 \mathrm{~d}$ & $\alpha$ & $\begin{array}{l}5830, \\
5792, \\
5790,5732\end{array}$ & $40-80 \mu \mathrm{m}$ \\
\hline${ }^{213} \mathrm{Bi}$ & $45.7 \mathrm{~min}$ & $\alpha$ & 5869 & $50-80 \mu \mathrm{m}$ \\
\hline${ }^{211} \mathrm{At}$ & $7.2 \mathrm{~h}$ & $\alpha$ & 5870 & $60-80 \mu \mathrm{m}$ \\
\hline${ }^{212} \mathrm{Bi}$ & $1 \mathrm{~h}$ & $\alpha, \beta$ & $\begin{array}{l}(\alpha): 6050 \\
(\beta): 2270\end{array}$ & $90 \mu \mathrm{m}$ \\
\hline${ }^{223} \mathrm{Ra}$ & $11.43 \mathrm{~d}$ & $\alpha$ & 5850 & $<100 \mu \mathrm{m}$ \\
\hline${ }^{169} \mathrm{Er}$ & $9.5 \mathrm{~d}$ & $\beta$ & $(\beta): 351$ & $1 \mathrm{~mm}$ \\
\hline${ }^{177} \mathrm{Lu}$ & $6.7 \mathrm{~d}$ & $\beta, \gamma$ & $(\beta): 500$ & $1.6 \mathrm{~mm}$ \\
\hline${ }^{67} \mathrm{Cu}$ & $2.58 \mathrm{~d}$ & $\beta, \gamma$ & $(\beta): 577$ & $2.2 \mathrm{~mm}$ \\
\hline${ }^{131} \mathrm{I}$ & $8.04 \mathrm{~d}$ & $\beta, \gamma$ & $(\beta): 807$ & $2.4 \mathrm{~mm}$ \\
\hline${ }^{89} \mathrm{Sr}$ & $50.53 \mathrm{~d}$ & $\beta$ & 1463 & $<3 \mathrm{~mm}$ \\
\hline${ }^{153} \mathrm{Sm}$ & $1.95 \mathrm{~d}$ & $\beta, \gamma$ & $(\beta): 233$ & $3 \mathrm{~mm}$ \\
\hline${ }^{198} \mathrm{Au}$ & $2.69 \mathrm{~d}$ & $\beta, \gamma$ & $(\beta): 1372.8$ & $4.4 \mathrm{~mm}$ \\
\hline${ }^{186} \mathrm{Re}$ & $3.77 \mathrm{~d}$ & $\beta, \gamma$ & $(\beta): 1069$ & $5 \mathrm{~mm}$ \\
\hline
\end{tabular}




\begin{tabular}{lllll}
\hline${ }^{165} \mathrm{Dy}$ & $2.33 \mathrm{~d}$ & $\beta, \gamma$ & $(\beta): 1286.1$ & $6.4 \mathrm{~mm}$ \\
\hline${ }^{32} \mathrm{P}$ & $14.3 \mathrm{~d}$ & $\beta$ & 1710 & $8.7 \mathrm{~mm}$ \\
\hline${ }^{166} \mathrm{Ho}$ & $26.9 \mathrm{~h}$ & $\beta, \gamma$ & $(\beta): 1853$ & $10.2 \mathrm{~mm}$ \\
\hline${ }^{188} \mathrm{Re}$ & $17 \mathrm{~h}$ & $\beta, \gamma$ & $(\beta): 2120$ & $11 \mathrm{~mm}$ \\
\hline${ }^{90} \mathrm{Y}$ & $64.1 \mathrm{~h}$ & $\beta$ & 2280 & $12 \mathrm{~mm}$ \\
\hline
\end{tabular}

Table 2. Linear Energy Transfer (LET) of therapeutic radionuclides ${ }^{18}$

\begin{tabular}{lll}
$\begin{array}{l}\text { Particle } \\
\text { Decay }\end{array}$ & Range in tissue & $\begin{array}{l}\text { LET } \\
(\mathbf{k e V} / \boldsymbol{\mu m})\end{array}$ \\
\hline$\alpha++$ & $\begin{array}{l}\text { (Cellular) } \\
100 \mu \mathrm{m}\end{array}$ & $\sim 80$ (High) \\
& $\begin{array}{l}\text { (Multi-cellular) } \\
0.05-12 \mathrm{~mm}\end{array}$ & $\sim 0.2$ (Low) \\
$\beta^{-}$ & $\begin{array}{l}\text { (Subcellular) } 2- \\
\text { 500 nm }\end{array}$ & \\
\hline EC/IC* $^{*}$ & 26 \\
\hline
\end{tabular}

* EC/IC: Electron Capture/Internal Conversion

With the actual improvement in the clinical outcome of cancer treatment, the reduction of the toxicity related to radiation has become a priority, together with the overcoming of some primary limitations of radiotherapy, i.e.; injury in surrounding tissues and tumor resistance. ${ }^{19,20}$ In this context, nuclear medicine has recently turned the attention to new oncologic strategies based on the nanovectorization of radiotherapy, generating the concept of radionanomedicine. ${ }^{21}$ The core of radionanomedicine relies on the labelling of nanomaterials with radionuclides to reduce the 
amounts of radiolabeled materials in vivo. ${ }^{22}$ Indeed, nanomedicine has traditionally been a major focus of nanotechnology. ${ }^{6}$ According to the US National Science Foundation, by 2020, nearly half of future pharmaceuticals will have some nanotechnology components. ${ }^{23,24}$ In recent years, there has been an unprecedented expansion in the field of nanomedicine with the development of new nanometric systems for better therapeutic efficacy and imaging quality of cancer. ${ }^{25}$ Nanosystems, compared to conventional medicines, have many benefits, given their nanometric size and large surface area-to-volume ratio, improved bioavailability, reduced toxicity, greater dose response, and enhanced solubility. ${ }^{26}$

Nanosystems with long circulation times can get internalized into tumors through the leaky tumor vasculature and be retained in the tumor due to abnormal lymphatic drainage. This process is known as the enhanced permeability and retention (EPR) effect. ${ }^{27}$ However, for an efficient EPR effect, the physicochemical properties of the nanosystems are as important as the tumor biology. While, EPR effect is quite helpful to passively target nanosystems in animal models, a full understanding of the differences in tumor biology and clearance mechanisms between individual human patients has yet to be established. ${ }^{28}$

Accordingly, innovative radionanopharmaceuticals are much awaited for targeting cancer, with therapeutic doses of internal radiation. Their efficacy is determined by the two constituting elements, the carrier and the trace amount of a radionuclide with a defined radiation type, but also by the injection modalities (intravenous or loco-regional injection). Ideal radiopharmaceuticals should transport the radioactive nuclide quantitatively to the tumor tissue, while protecting healthy tissues from radiation. Various kinds of carriers have been described for this purpose, including liposomes, carbon nanotubes, polymeric nanoparticles, nanocapsules, etc. Among them, dendrimers are especially appealing. Their controlled synthesis allows the preparation of well- 
defined monodisperse and globular nanovectors, characterized by a tunable size and precise number of peripheral groups, which determine their physicochemical properties and function (Fig.1). The number of peripheral groups in dendrimers increases exponentially with the generation number. Several approaches have been developed to conjugate dendrimers to paramagnetic or radionuclide chelators for MRI, fluorescence, CT, and radionuclide-based imaging. In addition, multimodal imaging agents with improved diagnosis accuracy have been described exploiting the unique structural characteristics of dendrimers. As an exhaustive analysis of all this literature falls outside the scope of this review, interested readers on the use of dendrimers in cancer imaging and chemotherapy are referred to specialized reviews. ${ }^{29-37}$ Herein, we will focus on the use of dendrimers in radiotherapy, including state of the art examples up to December 2015 and perspectives in an emerging field, which to the best of our knowledge has not been revised yet.

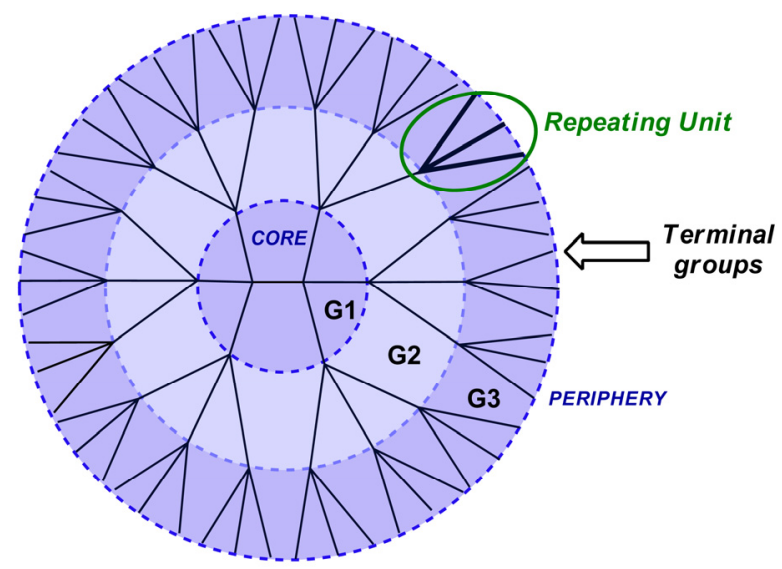

Figure 1. Schematic representation of a third generation (G3) dendrimer. 


\subsection{NANOVECTORIZED RADIOTHERAPY DRUGS APPROVED OR UNDER CLINICAL}

TRIALS

During the last decade, alpha $(\alpha)$, beta minus $\left(\beta^{-}\right)$and Auger electron-emitting radionuclides have been investigated for targeted and nanovectorized radiotherapy. Fortunately, these efforts have resulted in four targeted $\beta^{-}$emitters approved by FDA: ${ }^{153} \mathrm{Sm}$-EDTMP (Quadramet ${ }^{\circledR}$ ) and ${ }^{89} \mathrm{Sr}$-chloride $\left(\right.$ Metastron $^{\circledR}$ ) for palliation of bone metastases; and ${ }^{90} \mathrm{Y}$-ibritumomab $\left(\right.$ Zevalin $\left.^{\circledR}\right)$ and ${ }^{131}$ I-tositumomab $\left(\right.$ Bexxar $\left.^{\circledR}\right)$, for the treatment of B-cell non-Hodgkin's lymphoma. While Quadramet ${ }^{\circledR}$ and Metastron ${ }^{\circledR}$ consist of radioactive samarium $\left({ }^{153} \mathrm{Sm}\right)$ complexed to a tetraphosphonate chelator and a strontium-89 chloride $\left({ }^{89} \mathrm{SrCl}_{2}\right)$ injection, respectively, Zevalin ${ }^{\circledR}$ and Bexxar ${ }^{\circledR}$ are radiolabeled murine antibodies, directed against the CD20 antigen expressed on the surface of normal and malignant B-lymphocytes. ${ }^{38}$ The latter two are good examples of the potential benefit of antibody-guided systemic radionuclide-targeted therapy. ${ }^{39-46}$ In addition, several other radiopharmaceuticals for radio-immunotherapy of tumors have been introduced into clinical trials. More detailed information on these clinical trials is presented in the review of Gudkov and coworkers (Table 3$).{ }^{47}$

Table 3. Radio-immunotherapy drugs

\begin{tabular}{cccc} 
Generic Name & $\begin{array}{c}\text { Antigen/ } \\
\text { Radionuclide }\end{array}$ & Disease & $\begin{array}{c}\text { Clinical Trial } \\
\text { Status }\end{array}$ \\
\hline${ }^{90} \mathrm{Y}$-ibritumomab \\
tiuxetan & $\mathrm{CD} 20 /{ }^{90} \mathrm{Y}$ & $\begin{array}{c}\text { non-Hodgkin's } \\
\text { lymphoma }\end{array}$ & Approved by FDA \\
\hline${ }^{131}$ I-tositumomab & $\mathrm{CD} 20 /{ }^{131} \mathrm{I}$ & $\begin{array}{c}\text { non-Hodgkin's } \\
\text { lymphoma } \\
\text { non-Hodgkin's } \\
\text { lymphoma,chronic } \\
\text { lymphocytic leukemia }\end{array}$ & Approved by FDA \\
\hline
\end{tabular}


non-Hodgkin's

lymphoma, chronic

lymphocytic leukemia, immune diseases

\begin{tabular}{|c|c|c|c|}
\hline${ }^{131} \mathrm{I}-\mathrm{chTNT}-1 / \mathrm{B}$ & $\mathrm{DNA} /{ }^{131} \mathrm{I}$ & $\begin{array}{c}\text { glioblastoma, anaplastic } \\
\text { astrocytoma }\end{array}$ & Phase III \\
\hline CEA-Cide & CEA $/{ }^{90} \mathrm{Y}$ or ${ }^{131} \mathrm{I}$ & $\begin{array}{l}\text { breast, lung, pancreatic, } \\
\text { stomach, colorectal } \\
\text { carcinoma }\end{array}$ & Phase III \\
\hline pemtumomab & $\mathrm{PEM} /{ }^{90} \mathrm{Y}$ & $\begin{array}{l}\text { ovarian, gastric } \\
\text { carcinoma }\end{array}$ & Phase III \\
\hline${ }^{131} \mathrm{I}-$ metuximab & $\begin{array}{c}(\mathrm{Hab} 18 \mathrm{G} / \mathrm{CD} 14 \\
7) / 131 \mathrm{I}\end{array}$ & hepatocellular carcinoma & Phase II \\
\hline${ }^{131} \mathrm{I}-\mathrm{L} 19$ & Fibronectin $/{ }^{131} \mathrm{I}$ & $\begin{array}{l}\text { hepatological malignancy, } \\
\text { refractory Hodgkin's } \\
\text { lymphoma, non-small cell } \\
\text { lung cancer, melanoma, } \\
\text { head and neck carcinoma }\end{array}$ & Phase II \\
\hline $\begin{array}{c}{ }^{90} \mathrm{Y} \text {-clivatuzumab } \\
\text { tetraxetan }\end{array}$ & $\mathrm{MUC} 1 /{ }^{90} \mathrm{Y}$ & $\begin{array}{c}\text { pancreatic } \\
\text { adenocarcinoma }\end{array}$ & Phase III \\
\hline${ }^{223} \mathrm{Ra}$ dichloride & $-{ }^{223} \mathrm{Ra}$ & $\begin{array}{l}\text { metastatic castration- } \\
\text { resistant prostate cancer }\end{array}$ & Approved by FDA \\
\hline $\begin{array}{c}{ }^{177} \mathrm{Lu}-\text { DOTA-Tyr3- } \\
\text { Octreotate }\end{array}$ & $\mathrm{SST} /{ }^{177} \mathrm{Lu}$ & $\begin{array}{l}\text { metastatic Gastro-Entero- } \\
\text { pancreatic } \\
\text { Neuroendocrine tumors }\end{array}$ & Phase III \\
\hline${ }^{131} \mathrm{I}-\mathrm{MIBG}$ & $\begin{array}{l}\text { norepinephrine } \\
(\mathrm{NE}) /{ }^{131} \mathrm{I}\end{array}$ & $\begin{array}{c}\text { neuroblastoma, } \\
\text { pheochromocytoma, } \\
\text { paraganglioma }\end{array}$ & Phase III \\
\hline
\end{tabular}

${ }^{a}$ DOTA refers to 1,4,7,10-tetraazacyclododecane-1,4,7,10-tetraacetic acid.

\section{DENDRIMERS AS INNOVATIVE RADIOPHARMACEUTICALS}

The history of dendrimers goes back to the late 1970s and early 1980s, when the groups of Vögtle ${ }^{48}$ Newkome $^{49}$ and Tomalia ${ }^{50}$ independently published the first contributions in the area. Since then, more than a hundred dendritic structures have been described in the search of improved 
properties and innovative applications in fields like bio- and nanotechnology, catalysis or materials science. ${ }^{51-59}$ Nowadays, some of the most recognized dendritic families include polyamidoamine (PAMAM) ${ }^{60}$ polypropylene imine (PPI), ${ }^{61}$ and others based on polyamide, ${ }^{49}$ polyether ${ }^{62}$ polyester, ${ }^{63,64}$ and phosphorous-based scaffolds ${ }^{65}$ (Fig. 2).

Dendrimers are unique among nanomaterials since their stepwise synthesis allows creating welldefined and monodisperse structures with tunable size and number of terminal units. They have three main structural components: (i) an internal core, from which the dendritic branches grow, (ii) the layers of branches that define the dendrimer generation and, (iii) a multivalent peripheral shell. The number of terminal groups in dendrimers increases exponentially with the generation number. This characteristic is crucial to modulate the dendrimer solubility, making possible to overcome some fundamental issues in radiotherapy, such as solubility and dose delivery. The controlled architecture of dendrimers allows multiple possibilities for the simultaneous attachment of radionuclide chelators and targeting moieties. ${ }^{66}$

Historically, dendrimers have been synthesized following multiple reaction steps that involve long reaction times, tedious purifications, and sometimes reversible reactions potentially leading to structural defects. This could have led to an outdated perception that dendrimer synthesis is complex, slow, and costly. ${ }^{67}$ Several improvements, however, have been done recently that simplify and fasten up the synthesis of dendrimers, including the use of: (i) orthogonal chemistries to avoid the need of protecting groups and so reduce the number of reaction steps; ${ }^{68}$ (ii) "click" chemistry for irreversible, fast, and high yield reactions; ${ }^{69}$ (iii) hypercores and hypermonomers for the accelerated increase of size while preserving dendrimer properties; or (iv) various types of heterofunctional dendrimers. ${ }^{70}$ The design principle of dendrimers has been thoroughly reviewed 
elsewhere, according to the surface/interior chemistry, generation size, shape, flexibility/rigidity and composition. ${ }^{57,71}$

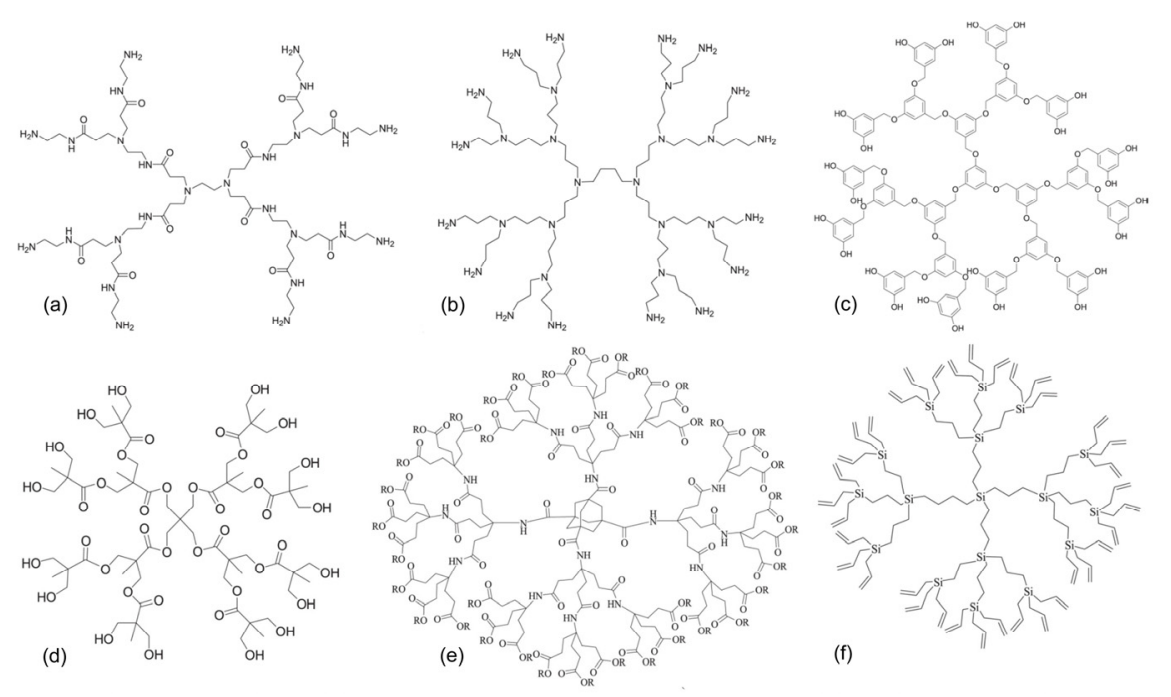

Figure 2. Structures of common dendrimers: (a) PAMAM; (b) PPI; (c) polybenzyl ether; (d) polyaliphatic ester; (e) polyesteramide; (f) polycarbosilane. ${ }^{51}$

\subsection{RADIOLABELED DENDRIMERS IN RADIOTHERAPY}

The first successful evidence of the therapeutic use of radioactive dendrimers came from a study with radioactive gold-dendrimer based nanoparticles of various sizes (Fig. 3). ${ }^{72}$ In this report, PAMAM dendrimers were used for the targeted delivery of the radiopharmaceutical to tumors in vivo. Poly- ${ }^{198} \mathrm{Au}^{0}$ nanoparticles were synthesized from non-radioactive ${ }^{197} \mathrm{Au}^{0}$-PAMAM complexes using both gamma-radiation and neutron radiation components in a reactor. 


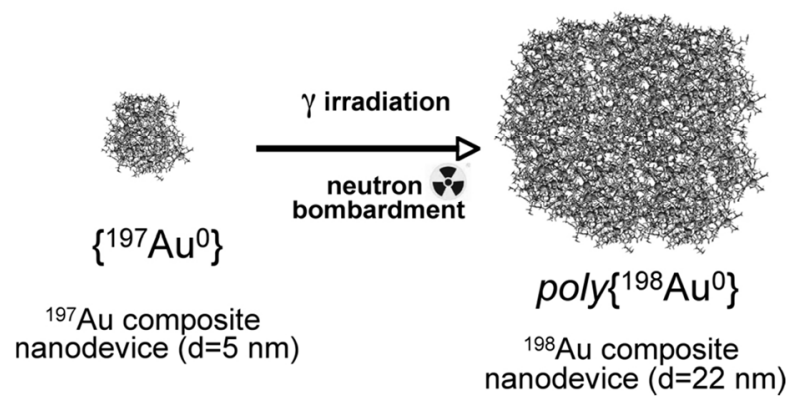

Figure 3. Polymerized composite nanoparticle formed by radiation of a dendrimer network with simultaneous neutron activation of ${ }^{197} \mathrm{Au}$ in the composite nanoparticles into ${ }^{198} \mathrm{Au}$. (Dark dots represent gold atoms, the organic network is grey. Reprinted from ref ${ }^{72}$ with permission from Elsevier, copyright 2008.

The increase in size of the resulting nanoparticles was due to partial crosslinking of the PAMAM dendrimers by the combined effect of gamma radiation and heat, while absorption of neutrons activated the gold component to ${ }^{198} \mathrm{Au}$. Biodistribution studies of both the template PAMAM dendrimers and the gold composites showed that positively charged nanoparticles were more retained in tissues than neutral or negatively charged ones. A single injection of ${ }^{198} \mathrm{Au}-\mathrm{PAMAM}$ complexes (29 $\mathrm{nm}$ in size) directly into a melanoma tumor mouse model resulted in more than a $45 \%$ decrease in tumor growth within 8 days.

\subsubsection{DENDRIMER- $\beta$ - EMMITER CONJUGATES}

The preclinical and clinical research in the field of dendrimer- $\beta^{-}$emitters has focused on at least twelve radionuclides: yttrium-90 $\left({ }^{90} \mathrm{Y}\right)$, iodine-131 $\left({ }^{131} \mathrm{I}\right)$, lutetium-177 $\left({ }^{177} \mathrm{Lu}\right)$, samarium-153 $\left({ }^{153} \mathrm{Sm}\right)$, strontium-89 $\left({ }^{89} \mathrm{Sr}\right)$, holmium-166 $\left({ }^{166} \mathrm{Ho}\right)$, rhenium-186 $\left({ }^{186} \mathrm{Re}\right)$, rhenium-188 $\left({ }^{188} \mathrm{Re}\right)$, copper-67 $\left({ }^{67} \mathrm{Cu}\right)$, promethium-149 $\left({ }^{149} \mathrm{Pm}\right)$, gold-199 $\left({ }^{199} \mathrm{Au}\right)$ and rhodium-105 $\left({ }^{105} \mathrm{Rh}\right) \cdot{ }^{73} \mathrm{In}$ addition, many radiotherapeutic $\beta^{-}$emitters also emit a low ratio of gamma photons $(\gamma)$ with energy 
in the ideal range for nuclear imaging ( 80 to $200 \mathrm{keV}$ ). Therefore, these radionuclides have theranostic properties, which are valuable in clinical radiotherapeutic applications with nanometric systems.

A radionuclide with excellent theranostic properties is ${ }^{188} \mathrm{Re}$ with a ratio of $85 \%$ for $\beta^{-}$emission $\left(E_{M}=2,12 \mathrm{MeV}\right)$ and $15 \%$ for $\gamma$ emission $(E=155 \mathrm{keV})$. Yu-Mei Shen and coworkers ${ }^{74}$ used $^{188} \mathrm{Re}$ to radiolabel G5 PAMAM dendrimers conjugated with 2-(4-isothiocyanatobenzyl)-6methyldiethylene-triaminepentaacetic acid (1B4M-DTPA) as a bifunctional ligand and folic acid (FA) for active targeting. The labelling yield of the conjugate G5-FA-DTPA- ${ }^{188}$ Re (percentage of incorporated radionuclide) was $67 \%$ and its radiochemical purity (the fraction of incorporated radioactivity that is present in the desired radiochemical form) exceeded 95\%. Even though the conjugate showed high in vitro stability when incubated for $6 \mathrm{~h}$ at $37^{\circ} \mathrm{C}$ in phosphate buffer saline (PBS, pH 7.4) or in new-born calf serum, a weak in vivo stability in mice revealed that further structural improvements were needed in the system.

In a preclinical study published in $2014,{ }^{75} \mathrm{G} 1$ and G4 PAMAM dendrimers conjugated with 10[(4-carboxy-1-oxidopyridin-2-yl)methyl]-1,4,7,10-tetraazacyclododecane-1,4,7-triacetic acid (DO3A-py ${ }^{\text {NO-C }}$, a DOTA-like bifunctional chelator with one methylene pyridine- $N$-oxide pendant arm) were radiolabeled with ${ }^{177} \mathrm{Lu}$ with high radiochemical purity. Both radiolabeled dendrimers were stable for at least $24 \mathrm{~h}$. As already seen in previous studies, ${ }^{76}$ the distribution profile of the G1 conjugate in organs and tissues of rats was more favorable than for G4. Conversely, the G4 conjugate with a considerably higher number of chelating ligands per molecule enables the binding of a larger number of radiometals. These results showed that dendrimer-radiometal chelates might constitute a prospective way to radiolabel targeting agents, such as antibodies or their fragments, with markedly high specific activity and minimal loss of their immunoreactivity. 
In a more recent study, ${ }^{77}$ theranostic dendrimers for targeted single-photon emission computed tomography (SPECT) imaging and radiotherapy of a MMP2-overexpressing xenografted glioma model in vivo (Fig. 4), were successfully constructed by the conjugation of a G5 PAMAM dendrimer with polyethylene glycol (PEG) and the targeting agents chlorotoxin (CTX) and 3-(4'hydroxyphenyl)propionic acid-OSu (HPAO). The dendrimer conjugates showed excellent cytocompatibility and could be effectively labeled with radioactive ${ }^{131} \mathrm{I}$ with good stability and high radiochemical purity. For in vivo imaging experiments, 6-week-old BALB/c female nude mice were inoculated subcutaneously with $2 \times 10^{6} \mathrm{C} 6$ cells/mouse in the right side of flank. At approximately 3 weeks post-injection, the tumors reached a volume of $0.5-1.0 \mathrm{~cm}^{3}$. The specific targeting role mediated by the attached CTX moiety onto the dendrimers was confirmed by the relatively higher tumor uptake of ${ }^{131}$ I-G5 NHAc-HPAO-(PEG-CTX)-(mPEG) dendrimers in comparison with non-targeted ${ }^{131}$ I-G5 NHAc-HPAO-(PEG-MAL)-(mPEG) dendrimers. It was seen that after treatment with ${ }^{131}$ I-G5 NHAc-HPAO-(PEG-CTX)-(mPEG), tumor grew more slowly than in mice treated with saline, $\mathrm{Na}^{131} \mathrm{I}$, or non-targeted ${ }^{131} \mathrm{I}-\mathrm{G} 5$ NHAc-HPAO-(PEGMAL)-(mPEG). The biodistribution study of the multifunctional dendrimers, investigated by SPECT imaging, showed that the majority of the ${ }^{131}$ I-G5 NHAc-HPAO-(PEG-CTX)-(mPEG) or ${ }^{131}$ I-G5 NHAc-HPAO-(PEGMAL)-(mPEG) dendrimers accumulated in the liver at $15 \mathrm{~h}$ postinjection, while the heart, lung, tumor, kidney, spleen, intestines, stomach, and soft tissue had a relatively low accumulation of the nanosystems. In spite of the high non-specific binding to normal tissue, CTX enhanced the accumulation of dendrimers in tumor compared to non-targeted dendrimers. At $24 \mathrm{~h}$ post-injection, the tumor SPECT signal descended for both targeted and nontargeted groups, indicating the dendrimer could be metabolized. Nevertheless, the SPECT signal 
intensity of tumors treated with the CTX-targeted dendrimer was still much higher than when treated with the non-targeted dendrimer.
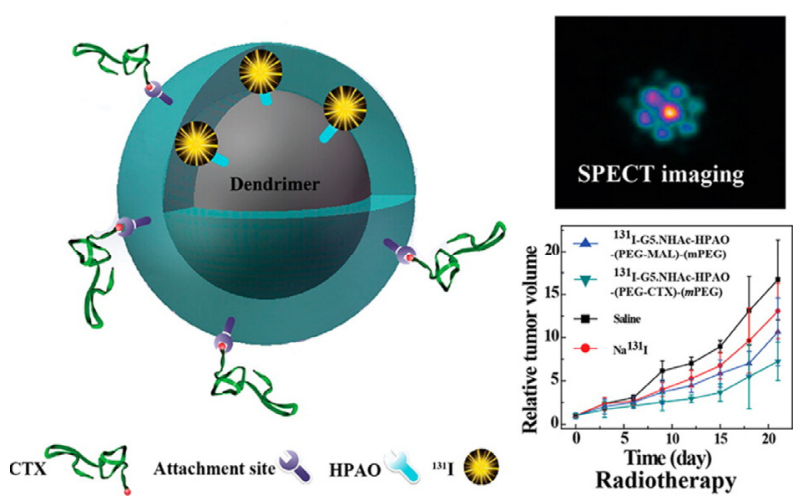

Figure 4. Chlorotoxin-conjugated multifunctional dendrimers labeled with radionuclide ${ }^{131}$ I for imaging and radiotherapy. Reprinted with permission from ref. ${ }^{77}$. Copyright 2015 American Chemical Society.

Similar multifunctional dendrimers have been synthesized by modifying G5 PAMAM dendrimers with HPAO and FA linked to PEG. ${ }^{78}$ After radiolabeling with ${ }^{131} \mathrm{I}\left({ }^{131} \mathrm{I}-\mathrm{G} 5 \cdot \mathrm{NHAc}-\mathrm{HPAO}-\mathrm{PEG}-\right.$ FA) the system was assayed for targeted SPECT imaging and radiotherapy, using a FA receptoroverexpressing xenografted tumor model in vivo. The radiolabeling of the dendrimer with ${ }^{131} \mathrm{I}$ was done via the chloramine $\mathrm{T}$ method with a radiochemical purity exceeding $97 \% .{ }^{131} \mathrm{I}-\mathrm{G} 5 \cdot \mathrm{NHAc}-$ HPAO-PEG-FA dendrimer displayed acceptable stability in vitro for at least $27 \mathrm{~h}$ when stored at room temperature in PBS. The relative SPECT signal intensity of different organs at $6 \mathrm{~h}$ and $24 \mathrm{~h}$ post-injection of ${ }^{131} \mathrm{I}-\mathrm{G} 5 \cdot \mathrm{NHAc}-\mathrm{HPAO}-\mathrm{PEG}-\mathrm{FA}$ and ${ }^{131} \mathrm{I}-\mathrm{G} 5 \cdot \mathrm{NHAc}-\mathrm{HPAO}-\mathrm{mPEG}$ dendrimers revealed that liver was the organ with the highest uptake, and a relatively low uptake from the other organs. Again, the tumor growth rate of mice injected with ${ }^{131} \mathrm{I}-\mathrm{G} 5 \cdot \mathrm{NHAc}-\mathrm{HPAO}-\mathrm{PEG}-\mathrm{FA}$ dendrimers was significantly slower than that of mice treated with saline, $\mathrm{Na}^{131} \mathrm{I}$, and control ${ }^{131} \mathrm{I}-$ 
G5 NHAc-HPAO-mPEG dendrimers without FA. This result underlines the importance of the effective FA targeting, also proven by the SPECT image at the tumor site.

Despite numerous investigations with dendrimers as conjugates for cancer drug therapy and imaging, ${ }^{29,32,79-85}$ there have been limited efforts in the development of radiotherapeutic dendrimers for image-guided radionuclide therapies. Current results are encouraging and point to a fruitful progress of dendrimer-chelate conjugates with bound $\beta^{-}$emitters and target-specific ligands in the area. Another new axis of research could be based on loco-regional injection of dendrimers, especially for glioma or hepatocarcinoma treatment, as confinement of the radiopharmaceuticals is expected, avoiding radiotoxicity to healthy tissues.

\subsubsection{DENDRIMER- $\alpha$ EMITTER CONJUGATES}

Medically relevant $\alpha$-emitting radionuclides currently available for potential therapeutic application are Astatine-211 $\left({ }^{211} \mathrm{At}\right)$, Bismuth-212 $\left({ }^{212} \mathrm{Bi}\right)$, Bismuth-213 $\left({ }^{213} \mathrm{Bi}\right)$, Actinium-225 $\left({ }^{225} \mathrm{Ac}\right)$, Radium-223 $\left({ }^{223} \mathrm{Ra}\right)$, Lead-212 $\left({ }^{212} \mathrm{~Pb}\right)$, Thorium-227 $\left({ }^{227} \mathrm{Th}\right)$, and Terbium-149 $\left({ }^{149} \mathrm{~Tb}\right) .{ }^{86}$ Recently, a pharmaceutical grade ${ }^{223} \mathrm{Ra}$ chloride solution was the first $\alpha$-emitting radiopharmaceutical to be approved for clinical use in the treatment of metastatic bone disease. ${ }^{87}$

Most approaches to target $\alpha$ particle emitters in the past relied on conjugation with antibodies through chelators. The efforts to integrate dendrimers in radiotherapy with $\alpha$ particles are limited to an early report from $\mathrm{Wu}, \mathrm{Gansow}$ and coworkers, ${ }^{88}$ who described a route to modify moAbs with a high number of chelating agents by conventional direct ligand attachment for use in radioimmunotherapy. This group successfully coupled with minimal loss of immunoreactivity a moAb with a single G2 PAMAM dendrimer carrying 10.2 of the available 12 surface primary amines decorated with 1,4,7,10-tetraazacyclododecane-1,4,7,10-tetraacetic acid (DOTA) or 
diethylenetriaminepentaacetic acid (DTPA) bifunctional ligands. Labeling the moAb-DTPA complex with ${ }^{212} \mathrm{Bi}$ resulted in at least four times greater specific activity than the previously obtained with a single DTPA conjugated to the moAb. In addition, radioyttrium labeling did not alter the immunoreactivity of the moAb-PAMAM-DOTA complex. Cold Gd(III) complexes also readily formed with the DOTA and DTPA-dendrimer-moAb conjugates. These positive results pave the way for the construction of successful dendrimer- $\alpha$ emitter conjugates for use in radiotherapy.

\subsubsection{DENDRIMER-AUGER ELECTRON EMITTER CONJUGATES}

Auger electron emitters under investigation in therapy include bromine-77 $\left({ }^{77} \mathrm{Br}\right)$, indium-111 $\left({ }^{111} \mathrm{In}\right)$, iodine-123 $\left({ }^{123} \mathrm{I}\right)$, and iodine-125 $\left({ }^{125} \mathrm{I}\right) \cdot{ }^{89}$ As for $\alpha$ particles, the precise subcellular localization of Auger emitters can dramatically affect their killing efficacy, with nuclear internalization resulting in significant efficiency compared to localization at the cell surface.$^{90}$ For instance, Auger electrons from neutron-activated Gd(III) are strongly cytotoxic, but only when Gd(III) ions have been internalized into cells. The group of Kobayashi ${ }^{91}$ used G6 PAMAM dendrimers conjugated with a DTPA derivative and avidin (Av-G6Gd), for targeted delivery of large quantities of $\mathrm{Gd}(\mathrm{III})$ into peritoneal carcinomatosis tumor cells with the aim of generating Auger emission with an external neutron beam. Av-G6Gd significantly accumulated and internalized into tumor cells both in vitro and in vivo, and the cytotoxic effect of the external irradiation with appropriate neutron beam was monitored with MRI (Fig. 5). 

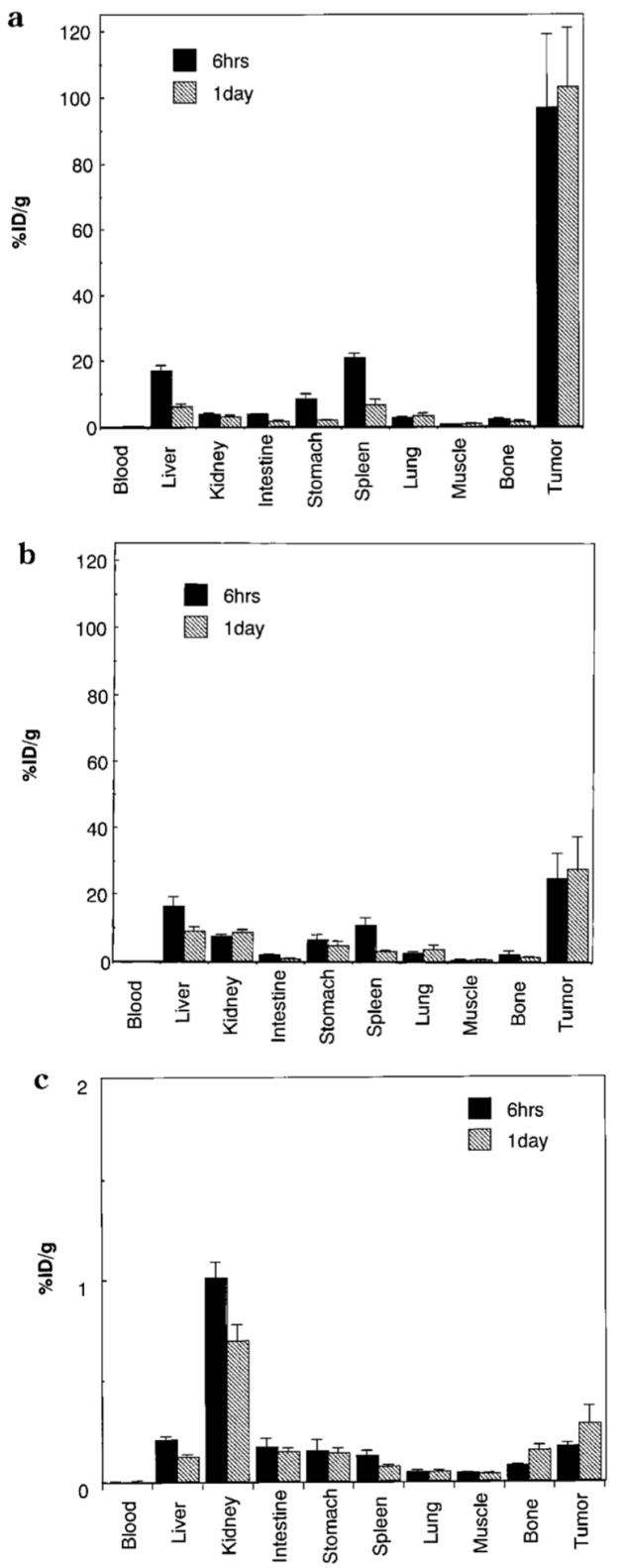

Figure 5. Biodistribution of ${ }^{153} \mathrm{Gd}-$ labeled Av-G6Gd (a), G6Gd (b), and Gd-DTPA (c) at 6 h (black bars) and 1 day (hatched bars) after i.p. injection in nude mice bearing SHIN3 intraperitoneal disseminated tumors. The data are expressed as the mean percentages of injected dose per gram of normal tissues and standard deviation $(n=4-6)$. All data show significant differences $(\mathrm{p}<0.01)$ compared with the appropriate group of data with Gd-DTPA. Reprinted with permission from ref. ${ }^{91}$ Copyright 2001 American Chemical Society. 
In another example by the same group, an Av-G4 PAMAM-1B4M chelate complex radiolabeled with ${ }^{111}$ In, which emits Auger and conversion electrons, was synthesized for internal radiation therapy in intraperitoneal (i.p.) disseminated tumors. ${ }^{92}$ The chelating sites on Av-G4-(1B4M) 52 were saturated with either radioactive or non-radioactive In(III). The results of this work clearly show the capability of Av-Bt-G4-(1B4M) 52 to specifically internalize cancer cells. The biodistribution studies of both ${ }^{111}$ In saturated and unsaturated dendrimers in nude mice demonstrated high dendrimer concentration in i.p. disseminated tumors with high tumor:background ratios.

In a more recent study, ${ }^{76} \mathrm{G} 1$ and G4 PAMAM dendrimers were conjugated with a bifunctional pyridine- $N$-oxide DOTA analog and radiolabeled with ${ }^{111}$ In. The conjugate displayed a good kinetic stability for at least $48 \mathrm{~h}$ after preparation. Biodistribution and elimination in rats was more favorable for the G1- ${ }^{111}$ In conjugate than for G4. Thus, while G1- ${ }^{111}$ In conjugate was rapidly eliminated from the body, mainly through urine, significant and long-term radioactivity uptake in the liver and kidney was observed for G4- ${ }^{111} \mathrm{In}$.

\subsubsection{DENDRIMERS IN BORON NEUTRON CAPTURE THERAPY}

Boron neutron capture therapy (BNCT) is a radiation therapy modality accomplished in two stages. First, a patient is injected with a non-radioactive pharmaceutical containing a stable isotope of boron $\left({ }^{10} \mathrm{~B}\right)$, which selectively migrates to cancer cells. Next, upon irradiation with a neutral beam of low-energy or thermal neutrons boron atoms generate $\alpha$ particles that destroy the tumor, leaving normal cells unaffected. In order to sustain a lethal effect a large number of ${ }^{10} \mathrm{~B}$ atoms must be delivered to each cancer cell..$^{93,94}$ 
The high cargo loading of dendrimers has been exploited to this end. Various dendrimers covalently attached to boron have been prepared and tested with preliminary positive results. A methodology was developed to heavily boronate a moAb by coupling to a boronated PAMAM dendrimer by means of heterobifunctional reagents. ${ }^{95}$ These conjugates retained the high in vitro immunoreactivity of the moAb, but after intravenous injection they accumulated in the liver. This way of injection resulted in a decrease of the in vivo tumor targeting properties of the conjugates. In order to avoid this biodistribution hurdle, an intratumoral injection of the boronated dendrimers was investigated with encouraging results. Later on, the same group ${ }^{96}$ has conjugated a heavily boronated G5 PAMAM dendrimer $\left(\mathrm{G}_{5}-\mathrm{B}_{1100}\right)$ to the Cetuximab ${ }^{\circledR}$ moAb, as a boron delivery agent for BNCT to brain tumor. When injected intracerebrally, the complex showed specific molecular targeting of the epidermal growth factor receptor (EGFR), which is often amplified in human gliomas.

In an effort to improve the biodistribution and decrease reticulo-endothelial system (RES) uptake, various studies have focused on the modification of boronated PAMAM dendrimers with PEG. Since the expression of the folate receptor is amplified in a variety of human tumors, FA is frequently used to enhance the tumoral uptake of dendrimers and other nanosystems. In this context, the group of Tjarks and coworkers ${ }^{97}$ evaluated a series of boronated G3 PAMAM dendrimers containing 12-15 decaborate clusters, along with PEG chains to minimize hepatic uptake and FA for folate receptor targeting. One of the conjugates having an average of one $\mathrm{PEG}_{2000}$ chain and one FA-PEG800 resulted in selective tumor uptake $(6.0 \% \mathrm{ID} / \mathrm{g}$ tumor) in C57BL/6 mice bearing folate receptor $(+)$ murine 24JK-FBP sarcomas. In spite of this result, high hepatic $(38.8 \% \mathrm{ID} / \mathrm{g})$ and renal $(62.8 \% \mathrm{ID} / \mathrm{g})$ uptakes were also revealed. The authors concluded 
that even though the strategy was successful in increasing tumor selectivity, further improvements were necessary to optimize biodistribution.

An alternative strategy to optimize the delivery of boronated dendrimers to tumor cells is the incorporation of carborane cages within the dendritic structure (Fig. 6). The group of Adronov ${ }^{98}$ synthesized a family of biocompatible water soluble, aliphatic polyester dendrimers that incorporate as many as $16 \mathrm{p}$-carboranes in their interior, as possible candidates for use in BNCT. In another example, phenylene-cored carborane dendrimers have been synthesized for BNCT ${ }^{99}$ In vitro studies with these dendrimers in human liver cancer cells showed a concentration-dependent accumulation of the dendrimer conjugates. Similarly, biocompatible Au nanoparticles containing carborane clusters and PEG chains attached to dendrons were engineered to provide a BNCT platform with potential simultaneous use in photo-thermotherapy, imaging and drug vectorization. ${ }^{100}$

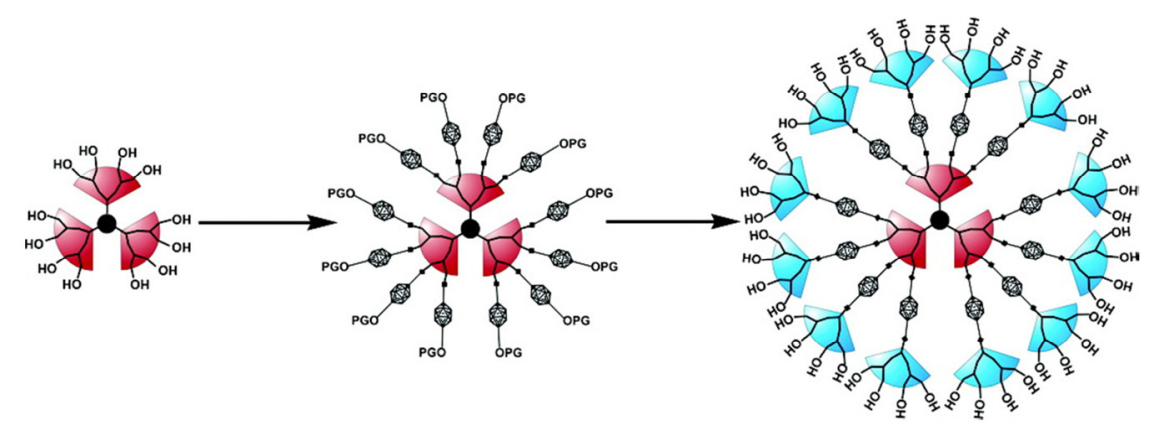

Figure 6. Schematic representation of the incorporation of carboranes into polyester dendrimers. Reprinted with permission from ref ${ }^{98}$. Copyright 2005 American Chemical Society.

The photoluminescence of different generations of porphyrin-cored aryl ether dendrimers functionalized with carborane clusters has been investigated. ${ }^{101}$ It was concluded that the photoluminescence properties of these dendrimers were not largely affected by the carboranes, opening the door for further investigations of these systems for theranostic use in nanomedicine. 
More recently, ${ }^{102}$ a dendritic wedge with high boron content for BNCT or boron MRI was combined with a monomethine cyanine dye for visible-light fluorescent imaging, and an integrin ligand for efficient tumor targeting. This conjugate resulted in a rapid intratumoral accumulation and prolonged retention when analyzed in fully established animal models of human melanoma and murine mammary adenocarcinoma (Fig. 7).

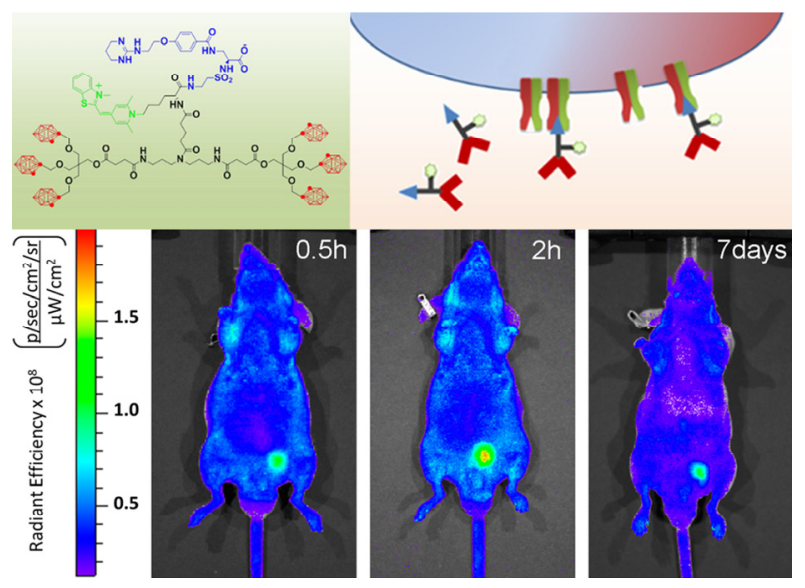

Figure 7. Representative fluorescence images of the in vivo tumor uptake of a trifunctional dendritic theranostic agent. Adapted with permission from ref ${ }^{102}$. Copyright 2014 American Chemical Society.

\subsection{DENDRIMER-ANTIBODY CONJUGATES IN RADIOIMMUNOTHERAPY}

Antibodies have the unique property to bind their targets in a highly selective manner, which makes them attractive for the delivery of radiotherapeutics. Phase I clinical trials have been performed with monoclonal antibodies (moAbs) radiolabeled with $\alpha$ emitters ${ }^{213} \mathrm{Bi}$ and ${ }^{211} \mathrm{At}$. These systems were evaluated in patients with leukemia and brain tumors, ${ }^{5}$ respectively, with encouraging responses and acceptable levels of toxicity in normal tissues.

The first bifunctional chelate used to bind ${ }^{213} \mathrm{Bi}$ to moAbs was trans-cyclohexyl diethylene triamine pentaacetic acid (CHX-A-DTPA), with a procedure requiring $0.5 \mathrm{~h} .{ }^{103}$ Other ligands 
derived from DTPA were later on synthesized for the same purpose, including the cyclic anhydride of diethylene triamine penta-acetic acid (cDTPAa) ${ }^{104}$ and p-isothiocyanatobenzyl-DTPA (CITCDTPA $)^{105}$. Zalutsky and coworkers ${ }^{106,107}$ developed a two-step method for the radiolabeling of intact or fragments of chimeric moAbs with ${ }^{211}$ At using two similar bifunctional chelating agents [N-succinimidyl 3-(tri-n-butylstannyl) benzoate (m-BuATE) and N-succinimidyl 3-(tri-nmethylstannyl) benzoate (m-MeATE)] in a procedure lasting $1.5 \mathrm{~h}$.

Tumor targeting studies with these radiolabeled moAbs showed, however, some limitations, such as insufficient targeting, low accumulation in tumor sites, and undesired irradiation of normal tissues associated to low clearance rates of IgG-based radioimmunoconjugates (days to weeks). ${ }^{108}$ Also, the introduction of more than one radionuclide per moAbs, to enhance the radioactive dose, caused a drastic decrease in immunoreactivity. The attachment of any therapeutic moiety to antibodies influences their clearance kinetics, biodistribution and side effects of radioimmunoconjugates. ${ }^{109}$ Another important issue in the use of moAbs for targeted radiotherapy was the slow reaction kinetics in the formation of the ligand-metal complex, when macrocyclic bifunctional chelating ligands, such as DOTA or DTPA derivatives, were attached to them. ${ }^{110,111}$ When the number of chelating groups into the structure of moAbs was increased to speed up complexation, a substantial loss in immunoreactivity was observed. ${ }^{112}$ The extent of antibody loading is a critical issue for the design of highly effective immunoconjugates, and still largely a subject of empirical evaluation. Indeed, amino acids amenable to modification are found along all regions of antibodies. Since most modification methods are not site-specific, there is no control over which amino acids are modified. This frequently results in immunoconjugates modified at positions weakening the binding to the antigen, which in turn decreases the efficacy of the targeting system. ${ }^{108}$ So, one of the actual challenges of immunoconjugation is product homogeneity with 
regard to site-specificity and stoichiometry of antibody modification. ${ }^{113,114}$ Site-specifically conjugated tumor-targeting antibodies have been shown to exhibit a greater uptake at the cancerous site and less non-specific uptake compared to heterogeneous immunoconjugates. ${ }^{115}$ The most challenging issue for radioimmunotherapy (RIT) is to find the correct balance between the dose delivered to the tumor and exposure of normal organs and tissues to radiation. ${ }^{116}$

Also, in order to improve tumor/blood ratios, antibody fragments lacking the Fc part have been tested for radio-immunoconjugation. ${ }^{117}$ Invariably, however, only a small fraction of the administered dose localizes in the tumor, rendering doses delivered to the tumor low for therapeutic applications.

In recent years, to solve these problems, dendritic systems have been conjugated to antibodies to preserve their immunoreactivity, while providing high specific activities and efficient radiolabeling. ${ }^{88,96,118}$ Indeed, the branched structure of dendrimers creates a multivalent surface with a high number of peripheral groups, which makes them unique candidates for conjugating to antibodies to afford log-fold higher radioactivities than current antibodies with promising results. ${ }^{119}$

The use of dendrimers for potentially improving delivery of radioimmunotherapy conjugates is in its early phases of development. One of the first reports in this area came from Roberts and coworkers, ${ }^{120}$ who conjugated PAMAM dendrimers to IgG-antibodies in a two-step process and demonstrated for the first time that their immunoreactivity remained largely unaffected after dendrimer conjugation using sensitive enzyme linked immunoassays (ELISA).

In 1999 the group of Kobayashi ${ }^{121}$ described the biodistribution of ${ }^{111}$ In and ${ }^{88} \mathrm{Y}$ labelled G2 PAMAM dendrimers conjugated to $1 \mathrm{~B} 4 \mathrm{M}$ and an anti-Tac IgG antibody. Tumor xenografts were generated in 5-6-week-old female athymic nude mice, with ATAC4 cell line. High tumor 
absorption of the conjugates was observed, although accompanied by high accumulation in liver, kidney and spleen that could be decreased by saturating the chelates with cold metals. Interestingly, saturation of the 1B4M chelates with $\mathrm{Y}$ (III) was shown to be more effective to decrease liver and spleen accumulation, in comparison with In(III). This fact probably relates a lower stability of the In(III) chelates in vivo that results in free 1B4M ligands and concomitant faster opsonization and uptake by RES.

In a more recent study by the same group, ${ }^{122} \mathrm{G} 4$ PAMAM dendrimers conjugated to $1 \mathrm{~B} 4 \mathrm{M}$ and OST7, a murine monoclonal IgG1, were labeled with ${ }^{111} \mathrm{In}$ and ${ }^{153} \mathrm{Gd}$. The radiometal labeling was achieved with very high specific radioactivity and minimal loss of immunoreactivity. Biodistribution studies in a mice model with KT005-specific tumors, showed specific tumor accumulation and rapid blood clearance. Again, the saturation of the 1B4M ligands with Gd(III) was more effective in decreasing liver and spleen accumulation than with In(III). Additionally, clearance times of unsaturated preparations were significantly slower than those of the saturated ones. As a result, it can be concluded that charge and molecular weight are not the only factors affecting biodistribution, and that the surface functionalization of dendrimers is critical to reduce their liver and spleen uptake.

The tumor selectivity of dendrimer-antibody conjugates has been investigated by Baker and coworkers. ${ }^{118}$ PAMAM dendrimers were conjugated to two different antibodies, 60bca and J591, which bind to CD14 and prostate-specific membrane antigen (PSMA), respectively. It was revealed that the antibody-conjugated dendrimers specifically bind to the antigen-expressing cells in a time and dose-dependent manner, with affinity similar to that of the free antibodies.

To study the effect of dendrimer size and number on the immunoreactivity of moAbs, several DOTA-containing PAMAM dendrimers of different generations were synthesized and conjugated 
to antibodies for radioimmunotherapy and clinical diagnostics (Fig. 8). ${ }^{123}$ It was concluded that the dendrimer size does not significantly influence the immunoreactivity of the conjugated antibody over a wide range of molecular weights, whereas increasing the number of conjugation sites has a clear detrimental effect. Therefore, to obtain conjugates that result in a minor compromise of immunoreactivity, antibodies should be functionalized with few large dendritic systems. Further studies are necessary to establish the clinical usefulness of dendrimer-conjugates for radioimmunotherapy

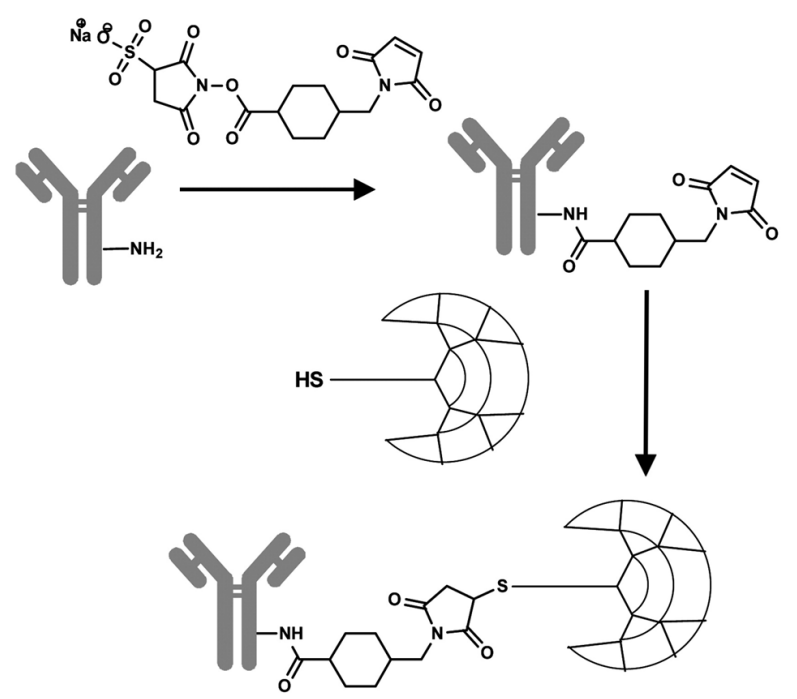

Figure 8. Scheme of the conjugation of DOTA-dendrimers to an antibody. Adapted with permission from ref ${ }^{123}$. Copyright 2008 American Chemical Society.

\subsection{DENDRIMERS IN GENE DELIVERY RADIOTHERAPY}

\subsubsection{DENDRIMERS IN RADIOVIROTHERAPY}

Radiovirotherapy is an innovative strategy for radioisotopic therapy that uses oncolytic viruses able to selectively target and kill cancer cells. ${ }^{124}$ The combination of oncolytic viruses and radiation can have synergistic antitumor properties by selectively delivering radiation therapy to tumor cells. 
The sodium/iodide symporter (NIS) is the main transgene that has been studied with this aim. ${ }^{125}$ NIS, is a trans-membrane glycoprotein that has a crucial role in the biosynthesis of thyroid hormones ${ }^{126}$ that is also known to be able to mediate the uptake of radionuclides, such as ${ }^{131} \mathrm{I},{ }^{188} \mathrm{Re}$ or ${ }^{211}$ At. While NIS expression in thyroid cancers decreases as the cancer cell differentiation decreases, ${ }^{127}$ NIS expression is found in a number of other non-thyroid cancers, like breast and liver. ${ }^{128-130}$ While, NIS expression in breast cancer cells is stimulated by retinoic acid (RA), estrogen and glucocorticoids, in the stomach the expression is generally suppressed during carcinogenesis. In liver cancers, NIS is expressed in all cholangiocarcinomas (CCA) and in a small proportion of hepatocellular carcinomas (HCC).

Accordingly, the use of a viral vector for NIS gene transfer to infected tumor cells is envisaged as a mean to improve the delivery of radioisotopes. Among the oncolytic viruses for this purpose, adenoviruses are the preferred vectors as they are known to selectively infect and replicate in cancer cells. Adenovirus-mediated gene therapy has nevertheless some limitations, such as high prevalence of neutralizing antibodies, widespread expression of the coxsackie-adenovirus receptor (CAR) and unexpected interactions with host proteins in vivo. In addition, targeting adenoviruses to receptors on hepatocytes results in vector sequestration in liver. ${ }^{131}$ Therefore with the aim of improving an efficacious targeting to tumor sites and limit nonspecific uptake of viruses to nontarget tissues (mainly liver and spleen) it has been necessary to develop suitable strategies to modify the capsid proteins on the virus shell, including the use of dendrimer coatings.

With the aim of developing adenoviral vectors for a combined systemic oncolytic virotherapy and NIS-mediated radiotherapy, the groups of Spitzweg and Ogris ${ }^{132}$ in collaboration recently used PAMAM dendrimers with positively charged terminal amines to coat the negatively charged adenoviral capsid of Ad5-E1/AFP-E3/NIS by electrostatic interactions. NIS expression was 
followed with noninvasive imaging by ${ }^{123} \mathrm{I}$ scintigraphy. In vivo tests in a liver cancer xenograft mouse model (Fig. 9) showed significantly lower hepatic accumulation of ${ }^{123} \mathrm{I}$ after systemic application. More importantly, the combined radiovirotherapy using the dendrimer-coated Ad5E1/AFP-E3/NIS (dc300Ad5-E1/AFP-E3/NIS), followed by a single application of a therapeutic dose of ${ }^{131} \mathrm{I}$, resulted in a stronger stimulation of the therapeutic effect, as observed by an extensively delayed tumor growth and prolonged survival in comparison with virotherapy alone or with control groups using the uncoated vector.

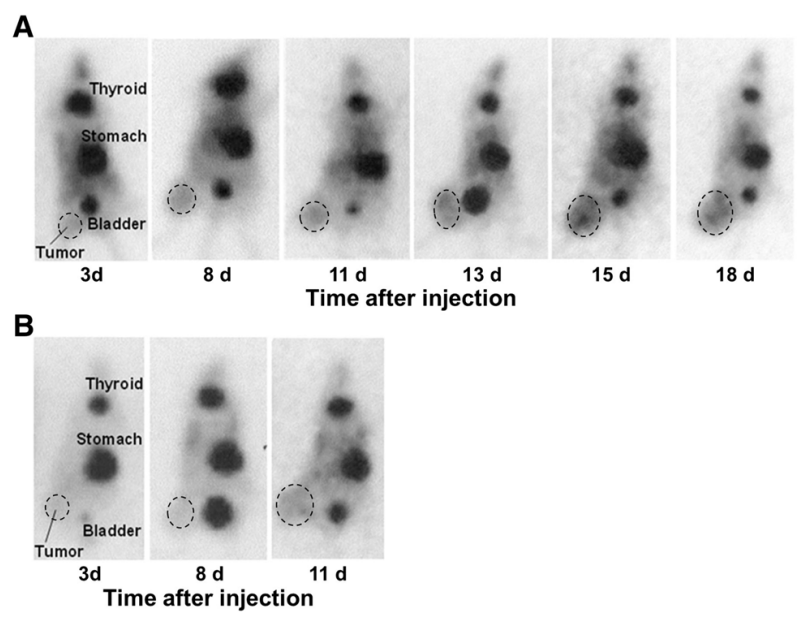

Figure 9. ${ }^{123}$ I scintigraphy confirms significantly increased levels of tumor-specific iodide accumulation after application of coated adenovirus (A) as compared with injection of uncoated virus (B). Reprinted from ref ${ }^{132}$, copyright by the Society of Nuclear Medicine and Molecular Imaging, Inc.

In another study from the same group, ${ }^{133}$ tumor-selective iodide uptake and therapeutic efficacy of combined radiovirotherapy was reported after systemic delivery of a theranostic NIS gene using a dendrimer-coated adenovirus. In this case the dendritic coating consisted of PAMAM dendrimers linked to an EGFR specific peptide ligand (GE11). As above, injection of the uncoated adenovirus in a liver cancer xenograft mouse model led to high levels of NIS expression in the liver due to 
hepatic sequestration, which were significantly reduced after dendrimer coating as demonstrated by ${ }^{123}$ I-scintigraphy. The EGFR targeting specificity was confirmed by ${ }^{124}$ I-PET-imaging (Fig.10), showing a significantly lower tumoral radioiodine accumulation after pretreatment with the EGFRspecific antibody cetuximab. The enhanced oncolytic effect following systemic application of the dendrimer-coated adenovirus was further increased by additional treatment with a therapeutic dose of ${ }^{131} \mathrm{I}$ (Fig.10).

Altogether, these results show that coating of adenoviral vectors with synthetic dendrimers is a promising strategy for effective adenovirus liver detargeting and tumor retargeting, taking advantage of the merging of nonviral and viral vector technologies.

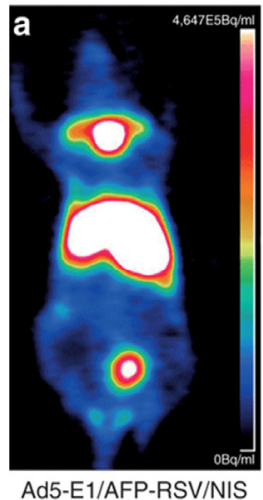

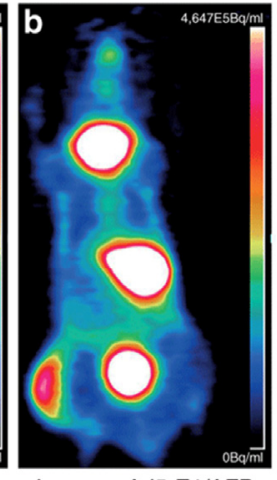

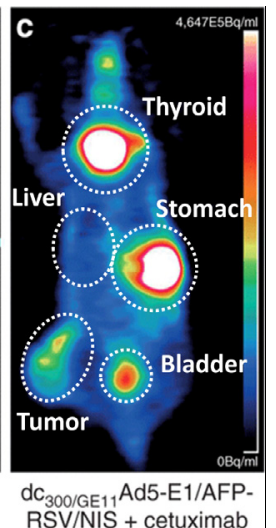

Figure 10. ${ }^{124}$ I-PET-imaging shows that the strong hepatic transduction after i.v. injection of an uncoated adenoviral vector (Ad5-E1/AFP-RSV/NIS) (a) is significantly reduced by coating with PAMAM-G2 linked to peptide GE11 (dc300/GE11Ad5-E1/AFP-RSV/NIS) (b), even when mice are treated with the monoclonal anti-EGFR antibody cetuximab before systemic administration (c). Significantly higher transduction of tumor xenografts was observed in (b) than (c). Adapted with permission from Macmillan Publishers Ltd: Mol. Ther. Nucleic Acids, ref ${ }^{133}$, copyright 2013. 


\subsubsection{DENDRIMERS IN COMBINED NON-VIRAL GENE DELIVERY AND}

RADIOTHERAPY

Since dendrimers by their own provide efficient and safe non-viral vectors for the delivery of genes into target cells, ${ }^{134}$ they have been also assayed for gene delivery radiotherapy. In a preclinical study, the groups of Spitzweg and Ogris ${ }^{135}$ used G2 oligoethylenimine (OEI)-grafted polypropylenimine dendrimers (PPI) as novel and highly efficient nonviral gene delivery vehicles for systemic NIS gene transfer (G2-HD-OEI/NIS) in a syngeneic neuroblastoma mouse model. Based on its dual function as reporter and gene therapy, NIS was used for noninvasive imaging of the biodistribution of the dendrimer conjugates by ${ }^{123}$ I-scintigraphy, followed by assessment of the therapy response after application of ${ }^{131}$ I. Tumor-specific iodide accumulation was shown to be sufficiently high for a significant delay of tumor growth, as observed by an increased survival rate after application of two cycles of NIS-dendrimer conjugates followed by ${ }^{131}$ I radiotherapy.

In a more recent contribution, ${ }^{136}$ the radiosensitivity of human uveal primary tumor, which is the most common primary intraocular tumor, was efficiently improved in vitro, when dendrimers were used as a vector to produce coexpression gene therapy of TNF $\alpha$ and HSV-TK, followed by exposure to ${ }^{125}$ I after transfection.

\section{CONCLUSIONS AND FUTURE PERSPECTIVES}

In order to improve the efficacy of internal radiotherapy as one of the most commonly used cancer treatments, nuclear medicine has recently turned the attention to new oncologic strategies based on nanovectorization, often referred to as radionanomedicine. The ultimate aim is to efficiently target and retain radiation at the tumor site, avoiding side effects, such as toxicity and tumor resistance process. Thus, it is known that nanosystems with long circulation times in the blood stream can get internalized and retained into tumors thanks to a leaky vasculature and an 
abnormal lymphatic drainage. This effect, known as EPR, can be further assisted by the use of targeting agents. The objective of radionanotherapy is the labeling of nanosystems with radionuclides to improve the efficiency of the treatment, while reducing the dose of radiolabeled materials in vivo. Among the nanosystems described for this purpose, dendrimers are especially appealing because of their multivalency, tunable size and physicochemical properties as a function of the generation. Milestones in the development of dendrimers for nanovectorized radiotherapy include their functionalization with ligands for radiolabeling, targeting agents, and stealth functional groups to potentially improve their biodistribution, circulation times and stability in vivo.

The active role of dendrimers as innovative radiopharmaceuticals is reviewed with a special focus on critical challenges encountered in the advance of targeted radiotherapy. As discussed, the radiolabeling of dendrimers with therapeutic radionuclides has resulted in tumor regression and longer survival. The biodistribution of dendritic conjugates can be improved by PEGylation, intratumoral application, saturation with cold metals, or by modulating their charge and molecular weight. In addition, the multifunctionality of dendrimers makes them excellent candidates for theranostics. For instance, optimized delivery of boron compounds to tumor cells was achieved by incorporating carborane cages within biodegradable dendrimers, which proved useful as theranostic agents in a combined use of BNCT, photo-thermotherapy, imaging and drug vectorization. The development of radiotherapeutic dendrimers for image-guided radionuclide therapies is also a work in progress. The multivalency and precise architecture of dendrimers can be exploited for radiotherapy in combination with moAbs, a strategy that pursues minor changes in immunoreactivity. Finally, dendrimers have been investigated in radiovirotherapy as coatings 
of adenoviral vectors for effective liver detargeting and tumor retargeting, as well as non-viral gene delivery vectors for NIS-targeted radionuclide therapy of metastatic cancer.

Although issues associated with in vivo properties and the toxicity of dendrimer conjugates are challenges to be addressed individually, as a whole there are considerable promise and benefits on current applications of dendrimers for radionanotherapy. A proper evaluation of dendrimer-based radiopharmaceuticals must be appreciated according to three criteria: the choice of radionuclide, the vector used, and the modalities of administration. Relatively recent results on dendrimer-based radiopharmaceuticals in preclinical models do not permit such a comparison yet. As discussed in this review, the physico-chemical properties of the radionuclide are crucial, but differences between vectors (untargeted vs targeted dendrimer, different dendrimer generations) are appreciated after intravenous injections with the aim of qualifying the targeting rather than the efficacy. In fact, for medical applications with radiopharmaceuticals, loco-regional injection could be a preferred way, where dendrimers play the role of confining agent at the injection site, in order to reduce the associated radio toxicity on healthy tissues or organs. Targeting will increase this confining action as needed for alpha-emitter and Auger-emitter.

\section{AUTHOR INFORMATION}

\section{Corresponding Authors}

*François Hindré, INSERM U 1066, 'Micro et Nanomédecines biomimétiques - MINT', and Université Angers, UMR-S1066, 49933 Angers, Cedex 9, France. Tel.: +33 2446885 29; Fax: +3324468 8546 e-mail: francois.hindre@univ-angers.fr

*Eduardo Fernandez-Megia, Centro Singular de Investigación en Química Biolóxica e Materiais Moleculares (CIQUS) and Departamento de Química Orgánica, Universidade de Santiago de 
Compostela, Jenaro de la Fuente s/n, 15782 Santiago de Compostela, Spain. Tel: +34 881815 727;

Fax: +34 881815 704; e-mail: ef.megia@usc.es; facebook.com/MegiaLab

\section{Notes}

The authors declare no competing financial interest.

\section{ACKNOWLEDGMENTS}

This work was financially supported by the Spanish Government (CTQ2015-69021-R, CTQ2012-34790, CTQ2014-61470-EXP) and the Xunta de Galicia (GRC2014/040) and by the "Institut National de la Santé et de la Recherche Médicale" (INSERM), by the "Axe Vectorisation and Radiothérapies" and the "Réseau Gliome Grand Ouest" (ReGGO) of the"Cancéropôle GrandOuest". The co-authors of this manuscript are also members of the LabEx IRON "Innovative Radiopharmaceuticals in Oncologyand Neurology" as part of the french government program "Investissements d'Avenir". F.L. thanks the European Commission, Education, Audiovisual and Cultural Executive Agency (EACEA) for an Erasmus Mundus grant under the NanoFar Joint Doctoral Program.

\section{REFERENCES}

(1)Bernier, J.; Hall, E. J.; Giaccia, A. Nat. Rev. Cancer 2004, 4, 737.

(2)Begg, A. C.; Stewart, F. A.; Vens, C. Nat. Rev. Cancer 2011, 11, 239.

(3)West, C. M.; Barnett, G. C. Genome Med. 2011, 3, 52.

(4)McDevitt, M. R.; Ma, D. S.; Lai, L. T.; Simon, J.; Borchardt, P.; Frank, R. K.; Wu, K.; Pellegrini, V.; Curcio, M. J.; Miederer, M.; Bander, N. H.; Scheinberg, D. A. Science 2001, 294, 1537.

(5)Couturier, O.; Supiot, S.; Degraef-Mougin, M.; Faivre-Chauvet, A.; Carlier, T.; Chatal, J.-F.; Davodeau, F.; Cherel, M. Eur. J. Nucl. Med. Mol. Imaging 2005, 32, 601.

(6)Akabani, G.; Carlin, S.; Welsh, P.; Zalutsky, M. R. Nucl. Med. Biol. 2005, 33, 333.

(7)Hassfjell, C. S., S. P. Int. J. Radiat. Biol. 2000, 76, 1315. 
(8)Wheldon, T. E.; O'Donoghue, J. A. Int. J. Radiat. Biol. 1990, 58, 1.

(9)Zaidi, H.; Sgouros, G. Therapeutic applications of Monte Carlo calculations in nuclear medicine; CRC Press, 2002.

(10)Kassis, A. I. Int. J. Radiat. Biol. 2004, 80, 789.

(11)Chen, P.; Wang, J.; Hope, K.; Jin, L.; Dick, J.; Cameron, R.; Brandwein, J.; Minden, M.; Reilly, R. M. J. Nucl. Med. 2006, 47, 827.

(12)Adelstein, S. J.; Kassis, A. I.; Bodei, L.; Mariani, G. Cancer Biother.Radiopharm. 2003, 18, 301.

(13)Unak, P. Braz. Arch. Biol. Technol. 2002, 45, 97.

(14)Hamoudeh, M.; Kamleh, M. A.; Diab, R.; Fessi, H. Adv. Drug Delivery Rev. 2008, 60, 1329.

(15)Tomblyn, M. Cancer Control 2012, 19, 137.

(16)Speer, T. W. Targeted radionuclide therapy; Lippincott Williams \& Wilkins, 2012.

(17)Audi, G.; Wapstra, A. Nucl. Phys. A 1995, 595, 409.

(18)Kassis, A. I. Semin. Nucl. Med. 2008, 38, 358.

(19)Korkolis, D. P.; Plataniotis, G. D.; Gondikakis, E.; Xinopoulos, D.; Koulaxouzidis, G. V.; Katsilieris, J.; Vassilopoulos, P. P. Int. J. Colorectal Dis. 2006, 21, 1.

(20)Pajonk, F.; Vlashi, E.; McBride, W. H. Stem Cells 2010, 28, 639.

(21)Vanpouille-Box, C.; Hindré, F. Front. Oncol. 2012, 2, 136.

(22)Lee, D. S.; Im, H.-J.; Lee, Y.-S. Nanomed. Nanotech. Biol. Med. 2015, 11, 795.

(23)McGrady, E.; Conger, S.; Blanke, S.; Landry, B. J. J. Healthc. Manag. 2010, 55, 353.

(24)Bharali, D. J.; Mousa, S. A. Pharmacol. Ther. 2010, 128, 324.

(25)Panchapakesan, B.; Wickstrom, E. Surg. Oncol. Clin. N. Am. 2007, 16, 293.

(26)Bawa, R. Curr. Drug Deliv. 2011, 8, 227.

(27)Maeda, H. Bioconjug. Chem. 2010, 21, 797.

(28)Prabhakar, U.; Maeda, H.; Jain, R. K.; Sevick-Muraca, E. M.; Zamboni, W.; Farokhzad, O.

C.; Barry, S. T.; Gabizon, A.; Grodzinski, P.; Blakey, D. C. Cancer Res. 2013, 73, 2412.

(29)Khan, M. K.; Nigavekar, S. S.; Minc, L. D.; Kariapper, M. S. T.; Nair, B. M.; Lesniak, W. G.;

Balogh, L. P. Technol. Cancer Res. Treat. 2005, 4, 603.

(30)Qiao, Z.; Shi, X. Prog. Polym. Sci. 2015, 44, 1.

(31)Liu, K.; Xu, Z.; Yin, M. Prog. Polym. Sci. 2015, 46, 25.

(32)Tomalia, D. A. Nanomed. Nanotech. Biol. Med. 2006, 2, 309.

(33)Svenson, S.; Tomalia, D. A. Adv. Drug Delivery Rev. 2005, 57, 2106.

(34)Koo, O. M.; Rubinstein, I.; Onyuksel, H. Nanomed. Nanotech. Biol. Med. 2005, 1, 193.

(35)Wolinsky, J. B.; Grinstaff, M. W. Adv. Drug Delivery Rev. 2008, 60, 1037.

(36)Menjoge, A. R.; Kannan, R. M.; Tomalia, D. A. Drug Discov. Today 2010, 15, 171.

(37)Kesharwani, P.; Iyer, A. K. Drug Discov. Today 2015, $20,536$.

(38)M. Goldenberg, D. Crit. Rev. Oncol. Hemat. 2001, 39, 195.

(39)Macklis, R. M.; Pohlman, B. Int. J. Radiat. Oncol., Biol., Phys. 2006, 66, 833.

(40)Davies, A. J. Oncogene 2007, 26, 3614.

(41)Jacene, H. A.; Filice, R.; Kasecamp, W.; Wahl, R. L. J. Nucl. Med. 2007, 48, 1767.

(42)Lang, J.; Lan, X.; Liu, Y.; Jin, X.; Wu, T.; Sun, X.; Wen, Q.; An, R. Nucl. Med. Biol. 2015, $42,505$.

(43)Kim, M.-k.; Jeong, H.-J.; Kao, C.-H. K.; Yao, Z.; Paik, D. S.; Pie, J. E.; Kobayashi, H.; Waldmann, T. A.; Carrasquillo, J. A.; Paik, C. H. Nucl. Med. Biol. 2002, 29, 139.

(44)Brady, L. W.; Woo, D. V.; Heindel, N. D.; Markoe, A. M.; Koprowski, H. Int. J. Radiat. Oncol., Biol., Phys. 1987, 13, 1535. 
(45)Lavie, E.; Boazi, M.; Weininger, J.; Bitton, M.; Yosilevski, G.; Front, D.; Hirshaut, Y.; Robinson, E.; Bartal, A. H. Radiother. Oncol. 1987, 8, 129.

(46)Epenetos, A. A.; Snook, D.; Hooker, G.; Lavender, J. P.; Halnan, K. E. The Lancet 1984, 324, 169.

(47)Gudkov, S.; Shilyagina, N.; Vodeneev, V.; Zvyagin, A. Int. J. Mol. Sci. 2016, 17, 33.

(48)Buhleier, E.; Wehner, W.; Vogtle, F. Synthesis 1978, $1978,155$.

(49)Newkome, G. R.; Yao, Z.; Baker, G. R.; Gupta, V. K. J. Org. Chem. 1985, 50, 2003.

(50)Tomalia, D. A.; Baker, H.; Dewald, J.; Hall, M.; Kallos, G.; Martin, S.; Roeck, J.; Ryder, J.; Smith, P. Polym. J. 1985, 17, 117.

(51)Wang, D.; Astruc, D. Coord. Chem. Rev. 2013, 257, 2317.

(52)Mintzer, M. A.; Grinstaff, M. W. Chem. Soc. Rev. 2011, 40, 173.

(53)Tekade, R. K.; Kumar, P. V.; Jain, N. K. Chem. Rev. 2009, 109, 49.

(54)Medina, S. H.; El-Sayed, M. E. Chem. Rev. 2009, 109, 3141.

(55)Dufes, C.; Uchegbu, I. F.; Schatzlein, A. G. Adv. Drug Delivery Rev. 2005, 57, 2177.

(56)Rolland, O.; Turrin, C.-O.; Caminade, A.-M.; Majoral, J.-P. New J. Chem. 2009, 33, 1809.

(57)Astruc, D.; Boisselier, E.; Ornelas, C. Chem. Rev. 2010, 110, 1857.

(58)Reek, J. N. H.; Arévalo, S.; van Heerbeek, R.; Kamer, P. C. J.; van Leeuwen, P. W. N. M. In Adv. Catal.; Bruce, C. G., Helmut, K., Eds.; Academic Press: 2006; Vol. Volume 49, p 71.

(59)Rosen, B. M.; Wilson, C. J.; Wilson, D. A.; Peterca, M.; Imam, M. R.; Percec, V. Chem. Rev. 2009, 109, 6275 .

(60)Esfand, R.; Tomalia, D. A. Drug Discov. Today 2001, 6, 427.

(61)de Brabander-van den Berg, E. M. M.; Meijer, E. W. Angew. Chem., Int. Ed. Engl. 1993, 32, 1308.

(62)Hawker, C. J.; Frechet, J. M. J. J. Am. Chem. Soc. 1990, 112, 7638.

(63)Carnahan, M. A.; Grinstaff, M. W. Macromolecules 2006, 39, 609.

(64)Ihre, H.; Padilla De Jesús, O. L.; Fréchet, J. M. J. J. Am. Chem. Soc. 2001, 123, 5908.

(65)Majoral, J. P.; Caminade, A. M. Chem. Rev. 1999, 99, 845.

(66)Patri, A. K.; Kukowska-Latallo, J. F.; Baker Jr, J. R. Adv. Drug Delivery Rev. 2005, 57, 2203.

(67)Svenson, S. Chem. Soc. Rev. 2015, 44, 4131.

(68)Wong, C.-H.; Zimmerman, S. C. Chem. Commun. 2013, 49, 1679.

(69)Lallana, E.; Fernandez-Trillo, F.; Sousa-Herves, A.; Riguera, R.; Fernandez-Megia, E. Pharm.

Res. 2012, 29, 902.

(70)Boas, U.; Heegaard, P. M. H. Chem. Soc. Rev. 2004, 33, 43.

(71)Kannan, R. M.; Nance, E.; Kannan, S.; Tomalia, D. A. J. Intern. Med. 2014, 276, 579.

(72)Khan, M. K.; Minc, L. D.; Nigavekar, S. S.; Kariapper, M. S. T.; Nair, B. M.; Schipper, M.;

Cook, A. C.; Lesniak, W. G.; Balogh, L. P. Nanomed. Nanotech. Biol. Med. 2008, 4, 57.

(73)Zalutsky, M. R. In Handbook of Nuclear Chemistry; Vértes, A., Nagy, S., Klencsár, Z., Lovas, R., Rösch, F., Eds.; Springer US: 2011, p 2179.

(74)Wei Cui, Y. Z., Xiaoping Xu, and Yu-Mei Shen Med. Chem. 2012, 8, 727.

(75)Laznickova, A.; Biricova, V.; Laznicek, M.; Hermann, P. Appl. Radiat. Isot. 2014, 84, 70.

(76)Biricová, V.; Lázničková, A.; Lázníček, M.; Polášek, M.; Hermann, P. J. Pharm. Biomed. Anal. 2011, 56, 505.

(77)Zhao, L.; Zhu, J.; Cheng, Y.; Xiong, Z.; Tang, Y.; Guo, L.; Shi, X.; Zhao, J. ACS Appl. Mater. Interfaces 2015, 7, 19798.

(78)Zhu, J.; Zhao, L.; Cheng, Y.; Xiong, Z.; Tang, Y.; Shen, M.; Zhao, J.; Shi, X. Nanoscale 2015, 7, 18169 . 
(79)Leiro, V.; Garcia, J. P.; Tomás, H.; Pêgo, A. P. Bioconjug. Chem. 2015, 26, 1182.

(80)Cheng, Y.; Zhao, L.; Li, Y.; Xu, T. Chem. Soc. Rev. 2011, 40, 2673.

(81)Majoros, I. J.; Myc, A.; Thomas, T.; Mehta, C. B.; Baker, J. R. Biomacromolecules 2006, 7, 572.

(82)Venditto, V. J.; Regino, C. A. S.; Brechbiel, M. W. Mol. Pharm. 2005, 2, 302.

(83)Xu, X.; Zhang, Y.; Wang, X.; Guo, X.; Zhang, X.; Qi, Y.; Shen, Y.-M. Bioorg. Med. Chem. 2011, 19, 1643.

(84)Zhang, Y.; Sun, Y.; Xu, X.; Zhang, X.; Zhu, H.; Huang, L.; Qi, Y.; Shen, Y.-M. J. Med. Chem. 2010, 53, 3262.

(85)Agashe, H. B.; Babbar, A. K.; Jain, S.; Sharma, R. K.; Mishra, A. K.; Asthana, A.; Garg, M.; Dutta, T.; Jain, N. K. Nanomed. Nanotech. Biol. Med. 2007, 3, 120.

(86)Fisher, D. R. Curr. Radiopharm. 2008, 1, 127.

(87)Colletti, P. M. Clin. Nucl. Med. 2013, 38, 724.

(88)Wu, C.; Brechbiel, M. W.; Kozak, R. W.; Gansow, O. A. Bioorg. Med. Chem. Lett. 1994, 4, 449.

(89)Humm, J. L.; Howell, R. W.; Rao, D. V. Med. Phys. 1994, 21, 1901.

(90)Boswell, C. A.; Brechbiel, M. W. J. Nucl. Med. 2005, 46, 1946.

(91)Kobayashi, H.; Kawamoto, S.; Saga, T.; Sato, N.; Ishimori, T.; Konishi, J.; Ono, K.; Togashi, K.; Brechbiel, M. W. Bioconjug. Chem. 2001, 12, 587.

(92)Mamede, M.; Saga, T.; Kobayashi, H.; Ishimori, T.; Higashi, T.; Sato, N.; Brechbiel, M. W.; Konishi, J. Clin. Cancer Res. 2003, 9, 3756.

(93)Barth, R. F.; Coderre, J. A.; Vicente, M. G. H.; Blue, T. E. Clin. Cancer Res. 2005, 11, 3987.

(94)Moss, R. L. Appl. Radiat. Isot. 2014, 88, 2.

(95)Barth, R.; Soloway, A. Mol. Chem. Neuropathol. 1994, 21, 139.

(96)Wu, G.; Barth, R. F.; Yang, W.; Chatterjee, M.; Tjarks, W.; Ciesielski, M. J.; Fenstermaker, R. A. Bioconjug. Chem. 2004, 15, 185.

(97)Shukla, S.; Wu, G.; Chatterjee, M.; Yang, W.; Sekido, M.; Diop, L. A.; Müller, R.; Sudimack, J. J.; Lee, R. J.; Barth, R. F.; Tjarks, W. Bioconjug. Chem. 2003, 14, 158.

(98)Parrott, M. C.; Marchington, E. B.; Valliant, J. F.; Adronov, A. J. Am. Chem. Soc. 2005, 127, 12081.

(99)Dash, B. P.; Satapathy, R.; Bode, B. P.; Reidl, C. T.; Sawicki, J. W.; Mason, A. J.; Maguire, J. A.; Hosmane, N. S. Organometallics 2012, 31, 2931.

(100)Li, N.; Zhao, P.; Salmon, L.; Ruiz, J.; Zabawa, M.; Hosmane, N. S.; Astruc, D. Inorg. Chem. 2013, 52, 11146.

(101)Cabrera-González, J.; Xochitiotzi-Flores, E.; Viñas, C.; Teixidor, F.; García-Ortega, H.; Farfán, N.; Santillan, R.; Parella, T.; Núñez, R. Inorg. Chem. 2015, 54, 5021.

(102)Dubey, R.; Kushal, S.; Mollard, A.; Vojtovich, L.; Oh, P.; Levin, M. D.; Schnitzer, J. E.; Zharov, I.; Olenyuk, B. Z. Bioconjug. Chem. 2015, 26, 78.

(103)Brechbiel, M. W.; Gansow, O. A. J. Chem. Soc., Perkin Trans. 1 1992, 1173.

(104)Abbas Rizvi, S. M.; Henniker, A. J.; Goozee, G.; Allen, B. J. Leuk. Res. 2002, 26, 37.

(105)Mishra, A. K.; Iznaga-Escobar, N.; Figueredo, R.; Jain, V. K.; Dwarakanath, B. S.; PerezRodriguez, R.; Sharma, R. K.; Mathew, T. L. Methods Find. Exp. Clin. Pharmacol. 2002, 24, 653. (106)Zalutsky, M. R.; Narula, A. S. Int. J. Rad. Appl. Instrum. A 1988, 39, 227.

(107)Zalutsky, M. R.; Garg, P. K.; Friedman, H. S.; Bigner, D. D. Proc. Natl. Acad. Sci. U. S. A. 1989, 86,7149 .

(108)Garnett, M. C. Adv. Drug Delivery Rev. 2001, 53, 171. 
(109)Allen, T. M. Nat. Rev. Cancer 2002, 2, 750.

(110)Broan, C. J.; Cox, J. P. L.; Craig, A. S.; Kataky, R.; Parker, D.; Harrison, A.; Randall, A. M.; Ferguson, G. J. Chem. Soc., Perkin Trans. 2 1991, 87.

(111)Ruegg, C. L.; Anderson-Berg, W. T.; Brechbiel, M. W.; Mirzadeh, S.; Gansow, O. A.; Strand, M. Cancer Res. 1990, 50, 4221.

(112)Brechbiel, M. W.; Gansow, O. A.; Atcher, R. W.; Schlom, J.; Esteban, J.; Simpson, D.; Colcher, D. Inorg. Chem. 1986, 25, 2772.

(113)Carter, P. J.; Senter, P. D. Cancer J. 2008, 14, 154.

(114)Junutula, J. R.; Bhakta, S.; Raab, H.; Ervin, K. E.; Eigenbrot, C.; Vandlen, R.; Scheller, R. H.; Lowman, H. B. J. Immunol. Methods 2008, 332, 41.

(115)Jeger, S.; Zimmermann, K.; Blanc, A.; Grunberg, J.; Honer, M.; Hunziker, P.; Struthers, H.; Schibli, R. Angew. Chem., Int. Ed. Engl. 2010, 49, 9995.

(116)Wu, A. M.; Senter, P. D. Nat. Biotechnol. 2005, 23, 1137.

(117)Sharkey, R. M.; Goldenberg, D. M. Adv. Drug Delivery Rev. 2008, 60, 1407.

(118)Thomas, T. P.; Patri, A. K.; Myc, A.; Myaing, M. T.; Ye, J. Y.; Norris, T. B.; Baker, J. R. Biomacromolecules 2004, 5, 2269.

(119)Gröhn, F.; Bauer, B. J.; Akpalu, Y. A.; Jackson, C. L.; Amis, E. J. Macromolecules 2000, 33, 6042.

(120)Roberts, J. C.; Adams, Y. E.; Tomalia, D.; Mercer-Smith, J. A.; Lavallee, D. K. Bioconjug. Chem. 1990, 1, 305.

(121)Kobayashi, H.; Wu, C.; Kim, M.-K.; Paik, C. H.; Carrasquillo, J. A.; Brechbiel, M. W. Bioconjug. Chem. 1999, 10, 103.

(122)Kobayashi, H.; Sato, N.; Saga, T.; Nakamoto, Y.; Ishimori, T.; Toyama, S.; Togashi, K.; Konishi, J.; Brechbiel, M. W. Eur. J. Nucl. Med. 2000, 27, 1334.

(123)Wängler, C.; Moldenhauer, G.; Eisenhut, M.; Haberkorn, U.; Mier, W. Bioconjug. Chem. 2008, 19,813 .

(124)Touchefeu, Y.; Franken, P.; J. Harrington, K. Curr. Pharm. Des. 2012, 18, 3313.

(125)Filetti, S.; Bidart, J.-M.; Arturi, F.; Caillou, B.; Russo, D.; Schlumberger, M. Eur. J. Endocrinol. 1999, 141, 443.

(126)Carrasco, N. Biochim. Biophys. Acta 1993, 1154, 65.

(127)Wapnir, I. L.; van de Rijn, M.; Nowels, K.; Amenta, P. S.; Walton, K.; Montgomery, K.; Greco, R. S.; Dohan, O.; Carrasco, N. J. Clin. Endocrinol. Metab. 2003, 88, 1880.

(128)Liu, B.; Herve, J.; Bioulac-Sage, P.; Valogne, Y.; Roux, J.; Yilmaz, F.; Boisgard, R.; Guettier, C.; Cales, P.; Tavitian, B.; Samuel, D.; Clerc, J.; Brechot, C.; Faivre, J. Gastroenterology 2007, 132, 1495.

(129)Tazebay, U. H.; Wapnir, I. L.; Levy, O.; Dohan, O.; Zuckier, L. S.; Zhao, Q. H.; Deng, H. F.; Amenta, P. S.; Fineberg, S.; Pestell, R. G.; Carrasco, N. Nat. Med. 2000, 6, 871.

(130)Altorjay, A.; Dohan, O.; Szilagyi, A.; Paroder, M.; Wapnir, I. L.; Carrasco, N. BMC cancer 2007, 7, 5 .

(131)Khare, R.; Chen, C. Y.; Weaver, E. A.; Barry, M. A. Curr. Gene Ther. 2011, 11, 241.

(132)Grünwald, G. K.; Vetter, A.; Klutz, K.; Willhauck, M. J.; Schwenk, N.; SenekowitschSchmidtke, R.; Schwaiger, M.; Zach, C.; Wagner, E.; Göke, B.; Holm, P. S.; Ogris, M.; Spitzweg, C. J. Nucl. Med. 2013, 54, 1450.

(133)Grunwald, G. K.; Vetter, A.; Klutz, K.; Willhauck, M. J.; Schwenk, N.; SenekowitschSchmidtke, R.; Schwaiger, M.; Zach, C.; Wagner, E.; Goke, B.; Holm, P. S.; Ogris, M.; Spitzweg, C. Mol. Ther. Nucleic Acids 2013, 2, e131. 
(134)Shcharbin, D.; Pedziwiatr, E.; Blasiak, J.; Bryszewska, M. J. Control. Release 2010, 141, 110.

(135)Klutz, K.; Russ, V.; Willhauck, M. J.; Wunderlich, N.; Zach, C.; Gildehaus, F. J.; Göke, B.; Wagner, E.; Ogris, M.; Spitzweg, C. Clin. Cancer Res. 2009, 15, 6079.

(136)Wang, Y.; Mo, L.; Wei, W.; Shi, X. Int. J. Nanomed. 2013, 8, 3805. 